\title{
Gall stone dissolution with methyl tert-butyl ether: how to avoid complications
}

\author{
A Hellstern, M Leuschner, H Frenk, H W Dillinger, W Caspary, U Leuschner
}

\begin{abstract}
Fifty of 52 patients with cholesterol gall bladder stones were treated with methyl tertbutyl ether. In 48 of $50(96 \%)$ patients the stones dissolved after an average interval of 9.5 hours. Mean stone size was $1.7 \mathrm{~cm}(0 \cdot 5-3.3$ $\mathrm{cm})$, mean stone number was $14 \cdot 6$ (1-70). Twelve patients (24\%) complained of nausea, a burning sensation, or vomiting. In one patient bile leakage occurred and another suffered haematobilia $(4 \%)$. The puncture set was improved, and a special basket was developed to extract stones that had escaped into the cystic duct. To prevent bile leakage or haemorrhage from the incision channel, a tissue adhesive was injected into the channel or ceruletid was administered subcutaneously before removing the catheter to induce contraction of the gall bladder. Thus we were able to treat 44 patients without any complications. Nausea and vomiting could be reduced if the treatment time was kept short and the perfusion volume was as low as possible. Methyl tert-butyl ether treatment is a successful treatment of gall bladder stones with few complications.
\end{abstract}

In 1985 Thistle's group introduced direct gall stone dissolution with methyl tert-butyl ether. ${ }^{12}$ The gall bladder is punctured percutaneously and transhepatically via the gall bladder bed under fluoroscopy. The puncture is technically easy and the treatment is speedy and inexpensive. There are, however, four hazards associated with percutaneous transhepatic litholysis:

(1) The gall bladder wall may be injured opposite the puncture site, either by the needle or the plastic introducer.

(2) Haematobilia may develop ${ }^{3}$ if a large vessel is punctured in the gall bladder bed.

(3) When the catheter is removed at the end of treatment, a bile leakage or a haemorrhage at the liver surface may develop. ${ }^{4}$

(4) Stone impaction may occur in the cystic duct during perfusion.

Besides these complications there are other undesirable side effects such as nausea, gas problems, vomiting, or abdominal discomfort.

We have now treated 50 patients with cholesterol stones of the gall bladder with methyl tertbutyl ether and have learned to prevent the above mentioned problems, or at least to cope with them. We report our experience.

Correspondence to: Dr U Leuschner, Zentrum der Inneren Medizin,

Universitätsklinik, TheodorStern-Kai 7, 6000 Frankfurt Main 70, Federal Republic of Germany.

Accepted for publication 16 October 1989
Patient selection for methyl tert-butyl ether treatment was done by oral or intravenous chole-
Patients and method cystography and computed tomography at $5 \mathrm{~mm}$ intervals. Only patients with radiolucent cholesterol stones of the gall bladder were selected. In 50 of 52 patients we succeeded in puncturing the gall bladder under local anaesthesia (Scandicain $1 \%$ ) and sedation (lormetazepam, Noctamid: 1$2 \mathrm{mg}$ iv) with a needle $\left(0.028^{\prime \prime}, 45 \mathrm{~cm}\right)$. In two patients we failed because of extreme obesity. Using the needle, a catheter (introducer: $5 \mathrm{FG}$, $20 \mathrm{~cm}$ ) was propelled into the gall bladder. A guide wire $\left(0.035^{\prime \prime}, 145 \mathrm{~cm}\right)$ was inserted in several loops through the introducer enabling placement of the perfusion catheter $(5 \mathrm{FG}, 70$ $\mathrm{cm}$ ) (all instruments by William Cook Europe, Bjaeverskov, Denmark). We subsequently injected enough contrast medium to produce overflow via the cystic duct. For stone dissolution we used methyl tert-butyl ether (Merck, Darmstadt, FRG). The methyl tert-butyl ether was high performance liquid chromatography grade and was not prepared further by us. Treatment started with $2 \mathrm{ml}$. The perfusion volume was increased but never exceeded the overflow volume, which was assessed fluoroscopically by contrast medium. Methyl tertbutyl ether was aspirated immediately from the gall bladder, at the latest within two minutes of contact time. Routine laboratory tests such as white cell count, red cell count, alanine amino transferase, aspartate transaminase, lactate dehydrogenase, and lipase were done before treatment, after treatment, and one week later.

\section{Results}

(1) The most important results are found in Table I. In five of the first 15 patients the gall bladder was very slender. Because of this the pyramid-shaped needle tip pressed the wall in the area of the gall bladder bed up to the contralateral wall. In two patients the needle even protruded into the contralateral wall before it penetrated. The same happened with the introducer. From patient 16 onwards therefore we used a needle with an oblique cut and a better introducer, slanted at its tip at an angle of $30^{\circ}$ (Angiomed, Karlsruhe, FRG). These instruments were used successfully on 35 patients. With the use of the oblique cut needle, puncture of the gall bladder was especially easy when the wall was thickened. The slanted introducer cannot injure the gall bladder wall and the guide wire propelled through it is immediately bent into the gall bladder lumen when leaving the introducer tip.

(2) Just after insertion of the catheter a haematobilia developed in patient 8 (Fig 1). We aspirated blood for 3.5 hours via the perfusion catheter. At the same time a large clot formed in the gall bladder. After perfusion with an $0.9 \%$ 
TABLE I Results of methyl tert-butyl ether treatment in 50 patients with gall bladder stones

\begin{tabular}{lllllllll}
\hline $\begin{array}{l}\text { Age } \\
\text { (yrs) }\end{array}$ & No & $\begin{array}{l}\text { Stone } \\
\text { size }(\mathrm{cm})\end{array}$ & Volume $(\mathrm{cm})^{\star}$ & $\begin{array}{l}\text { Dissolution } \\
\text { time }(h)^{\dagger}\end{array}$ & Success & $\begin{array}{l}\text { Side } \\
\text { effectsł }\end{array}$ & ComplicationsS \\
\hline Mean & $46 \cdot 2$ & $14 \cdot 6$ & $1 \cdot 7$ & $24 \cdot 8$ & $9 \cdot 5$ & $48(96 \%)$ & $12(24 \%)$ & $2(4 \%)$ \\
\hline Range & $23-69$ & $1-70$ & $0 \cdot 5-3 \cdot 3$ & $1 \cdot 1-44 \cdot 6$ & $2 \cdot 5-21$ & - & - & - \\
\hline
\end{tabular}

^Stone volume: number $\times$ size $(\mathrm{cm})$.

TTreatment was interrupted during the night.

$\ddagger$ Nausea, vomiting, burning, pain, leucocytosis up to $16000 / \mathrm{mm}^{3}$.

§Bile leakage, haematobilia.

saline and a $1 \%$ ethylenediaminetetra-acetic acid and $5 \%-\mathrm{N}$-acetyl-cysteine-containing aqueous solution $^{5}$ for nine hours the clot dissolved completely and the gall stone was then dissolved with methyl tert-butyl ether (Table II, Fig 2). Since bile seems to be able to dissolve blood clots, however, the question arises as to whether it is necessary to do anything in such a case.

(3) In two of six patients (patients 3 and 4), bilecontaining contrast medium was seen on the monitor to follow the catheter tip through the liver when the perfusion catheter was removed (Fig 3). Both patients, plus patient 2, complained of pain on the right side. Necropsy studies on three livers of patients other than gall stone patients showed that the incision channel is not occluded after removal of the catheter and may be completely rechannelled from the liver surface by injection of methylene blue. Patient 6 had a bile leakage from the liver surface lasting 10 hours after the catheter was removed. The patient did not develop peritonitis but had severe pain and was able to be operated on without complications. Another option might have been the placement of a nasobiliary tube, but we did not try this in our patient.

For treatment of haematobilia and prevention of haemorrhage or bile leakage from the liver surface, we have developed the following method in three post mortem livers and three gall stone patients. The fibrin sticker Tissucol (Immuno GmbH, Heidelberg, FRG) is mixed in a ratio of 10:1 with $x$ ray contrast medium - for example, Conray 50 (Schering, Berlin, FRG). A guide wire is introduced, the perfusion catheter is removed after complete evacuation of the gall

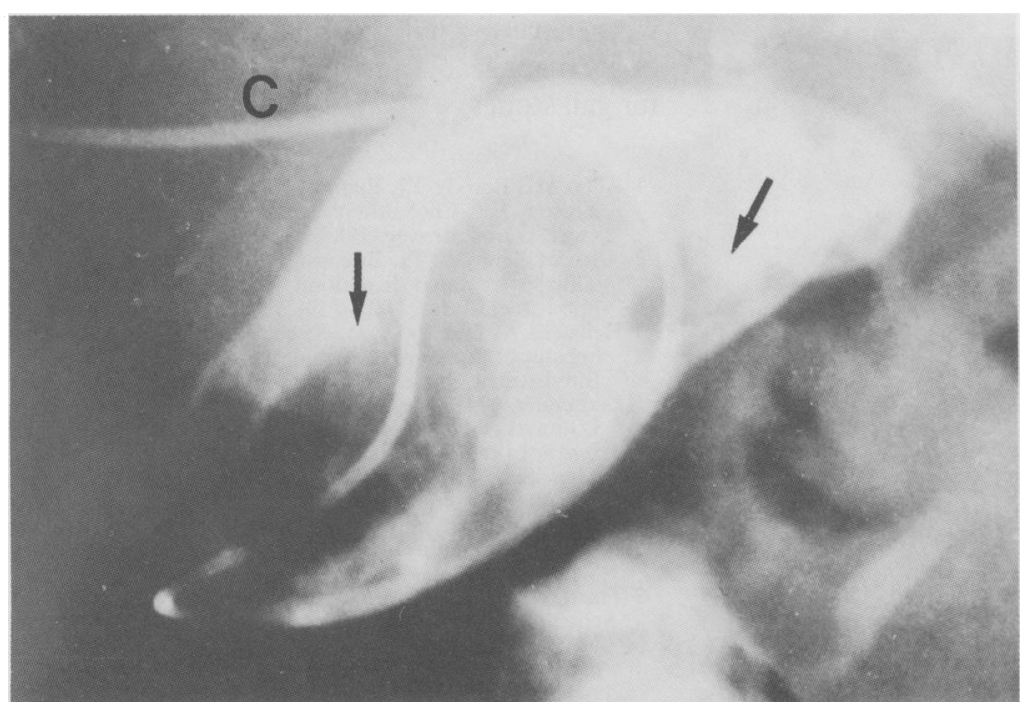

Figure 1: Patient 8. The gall bladder is completely filled with blood clots (arrows), and the stones are not visible. $C=$ catheter in the liver.

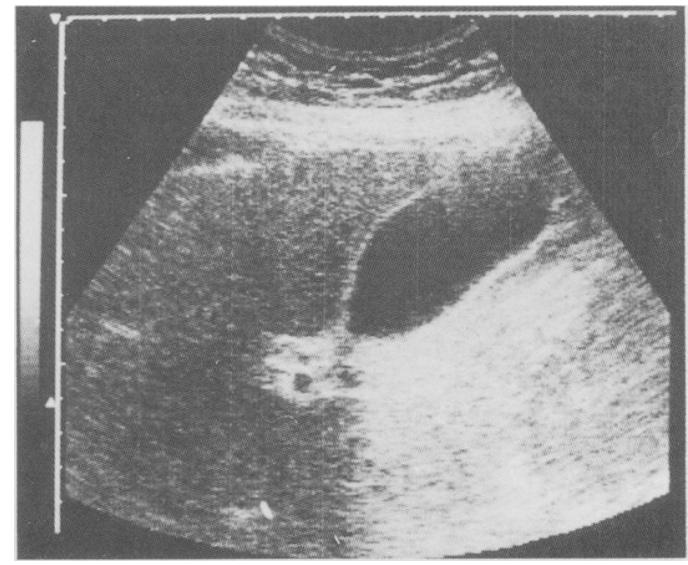

Figure 2: Patient 8. Four days after the gall bladder has been flushed with an EDTA solvent (Table II) and 0.9\% saline the gall bladder is free and the stones have been dissolved with methyl tert-butyl ether.

bladder, and a hollow needle is inserted via the wire into the channel of the liver. Tissucol, in an amount corresponding to the idle space of the needle, is carefully injected into the hollow needle. After 20-30 seconds the sticker is viscous and may be deposited under fluoroscopy anywhere in the incision channel (Fig 4(a) and (b)), in the case of treatment of a haematobilia, for instance, in the gall bladder bed. By depositing multiple plaques, the entire channel may be occluded. The sticker must be allowed to congeal in the hollow needle, in its liquid state it would flow through the incision channel into the gall bladder and provide a nucleus for new stones.

To prevent a bile leakage we used a different method from patient 7 onwards. After stone dissolution the gall bladder is completely evacuated with a syringe while the catheter is slowly removed. When only $3-5 \mathrm{~cm}$ of the perfusion catheter are still positioned in the gall bladder, we inject $5 \mu \mathrm{g}$ ceruletid (Takus, Farmitalia, FRG) subcutaneously into the thigh. After three minutes the gall bladder has contracted and the catheter can be removed. Subsequent ultrasound scans showed marked contraction in 38 patients, and appreciable contraction in six patients. Only five of the patients treated this way reported pain at the incision site. In none of them did we see the incision channel filled with contrast medium in the liver, nor did we see bile leakage.

(4) Impaction of a small stone in the cystic duct occurred in patient 4 during perfusion treatment. We manoeuvred the catheter tip near the stone after failing to move it with the guide wire: the stone was dissolved. To be able to handle this complication more easily we have developed a basket (similar to a Dormia basket) which can be

TABLE II Solvent used for treatment of haematobilia

\begin{tabular}{llc}
\hline BA-EDTA-NAC & $\%(w / w)$ & mmol/l \\
\hline EDTA-2Na & 1.0 & 26.9 \\
Cholic acid & 0.5 & 12.3 \\
Ursodeoxycholic acid & 0.5 & $12 \cdot 7$ \\
Carnosin & 0.5 & 18.0 \\
Arginin & 1.9 & 109.0 \\
Nacetyl-cysteine & 5 & \\
N-aOH, $\mathrm{H}_{2} \mathrm{O}: \mathrm{pH} 9 \cdot 2$ & & \\
\hline
\end{tabular}

EDTA $=$ ethylenediaminetetra-acetic acid. 


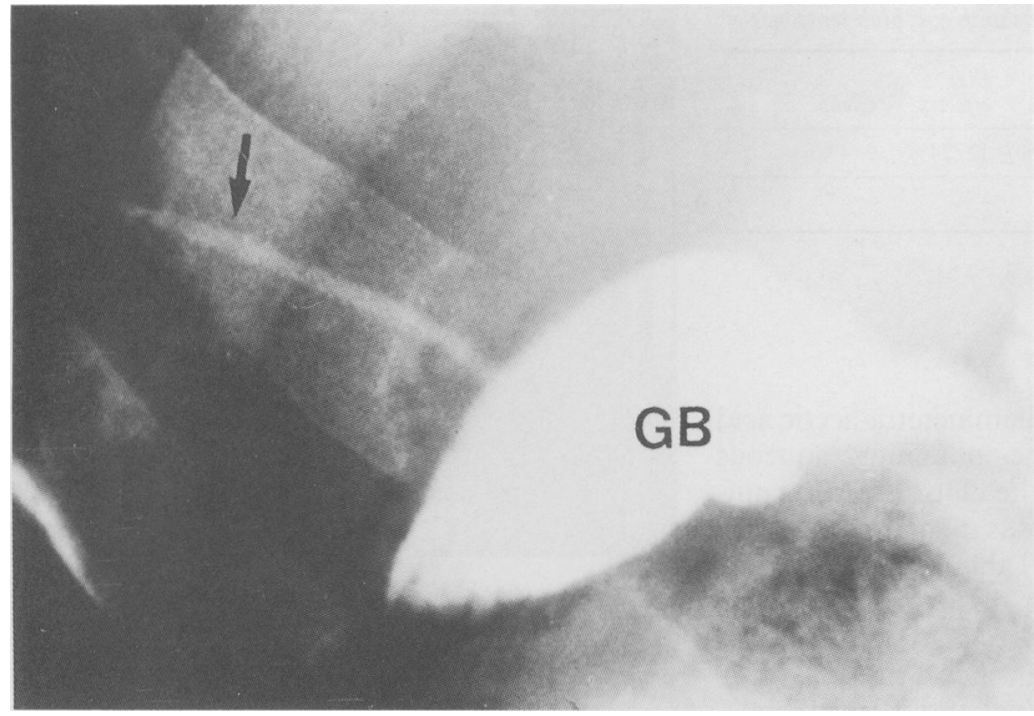

Figure 3: Patient 4. The catheter has been removed, and bile mixed with contrast medium (arrow) has followed the tip of the catheter through the incision channel. GB=gall bladder.

easily introduced through the 5 FG introducer and will move impacted stones (available from Pauldrach, Garbsen, FRG).

Adverse reactions to methyl tert-butyl ether treatment such as nausea, vomiting, gas, a burning sensation, or tenderness can easily be reduced or even prevented if the catheter is placed early in the morning and, if possible, removed on the same day after treatment. Complaints will increase if the catheter is left in the gall bladder for two days. So that methyl tertbutyl ether does not flow into the gut, the perfusion volume should not exceed an amount which just envelops all the patient's stones. Usually, $10 \mathrm{ml}$ of methyl tert-butyl ether are sufficient as a maximum individual dose. After four to six hours, when the stones have reduced, the catheter position must be checked. Thus, we can reduce the perfusion volume, which prevents side effects. If these recommendations are taken into account, administration of antiemetics or analgesics can be completely avoided.

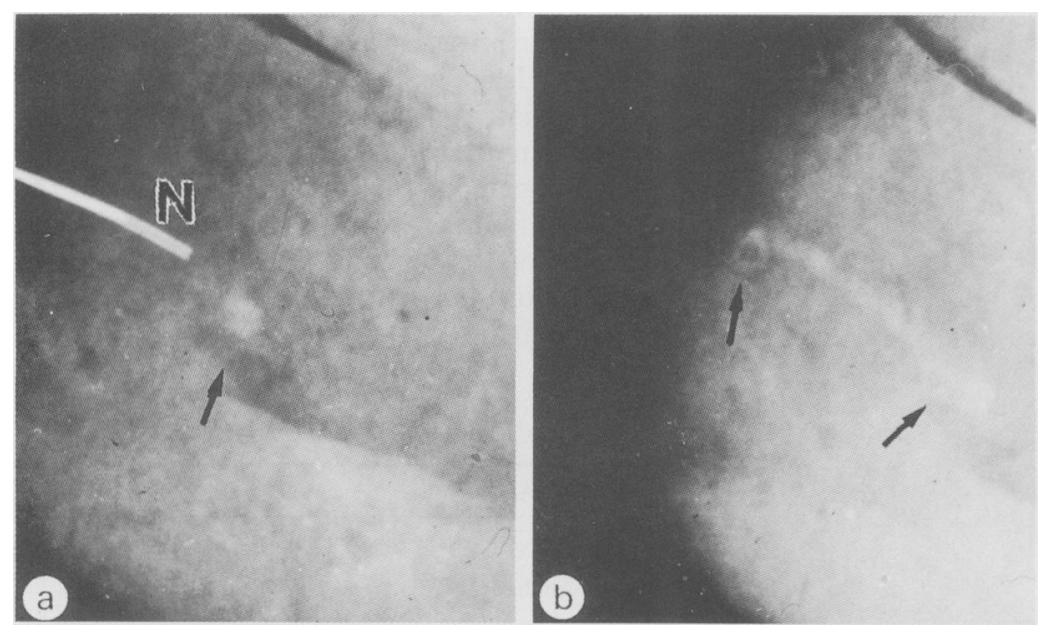

Figure $4(a)$ : The hollow needle $(N)$ is still in the liver. The arrow marks a plaque of the fibrin adhesive Tissucol (fibrinogen, fibronectin, FXIII in aprotinin thrombin) mixed with contrast medium located in the incision channel.

(b) The entire channel (arrows) is closed by the fibrin adhesive.

\section{Discussion}

Stone dissolution was achieved in 48 of 50 patients $(96 \%)$. In one patient in whom a bile leakage occurred we decided to operate. In two patients we saw bile-containing contrast medium in the incision channel of the liver when the catheter was removed. Since these two and a third patient complained of pain in the area of the incision site, we presume that they experienced bile leakage at the liver surface too.

In the following 46 patients we did not observe any bile leakage after administering ceruletid. Only rarely were there reports of mild pain at the puncture site and the gall bladders were markedly contracted in almost all patients. No bile is able to pass into the incision channel and we believe that ceruletid is an excellent means of preventing this.

The fibrin sticker Tissucol was not used as a routine measure. The placing of Tissucol plaques in the incision channel is technically very easy, and haematobilia can be treated in this way. Haemorrhage from the liver surface and bile leakage cannot be treated, however, since the instruments have been removed at this point. If these complications are a possibility, the fibrin sticker should be inserted into the entire incision channel as a preventive measure, and only then should the instruments be removed.

Side effects such as haemolysis ${ }^{6}$ or renal failure ${ }^{7}$ were not observed.

After improvement of the puncture instruments and the development of simple measures for prevention and treatment of leakages, we consider methyl tert-butyl ether treatment to be safe. To limit the patient's side effects to a minimum, one should try not to let the perfusion duration exceed half a day (approximately 12 hours). Fast, continuous treatment is the safest way to prevent undesirable side effects.

While percutaneous transhepatic methyl tertbutyl ether treatment in the gall bladder could be expanded to include treatment of gall stone cholecystitis, ${ }^{8}$ or by admixture of other solvents to treating pigment stones, ${ }^{910}$ we do not believe that it is suitable for the treatment of bile duct stones because of the considerable side effects. ${ }^{11-14}$ In agreement with J Thistle $e t$ al,$^{15}$ who have recently published data on 75 patients, we believe methyl tert-butyl ether treatment is easily manageable and highly effective treatment for gall stones.

1 Allen MJ, Borody TJ, Bugliosi TF, May GR, LaRusso NF Thistle JL. Cholelitholysis using methyl tertiary-buty Thistle JL. Cholelitholysis using meth

2 Allen MJ, Borody TJ, Bugliosi TF, May GR, LaRusso NF, Thistle JL. Rapid dissolution of gallstones by methyl tertbutyl ether. N Engl f Med 1985; 312: 217-20.

3 Hellstern A, Leuschner M, Fischer $\mathrm{H}$, et al. Perkutantranshepatische Lyse von Gallenblasensteinen mit Methyl-tertButyl-Äther. Dtsch Med Wochenschr 1988; 113: 506-10

4 Leuschner U, Hellstern A. Perkutan-transhepatische Litholyse (PTL) mit Methyl-tert-Butyl-Âther (MTBE). Der Internist 1988; 29: 788-91.

5 Wosiewitz U, Güldütuna S, Fischer H, Leuschner U. Pigment gallstone dissolution: solubilization of brown bilirubinate and black polybilirubinate stone material by buffered solvents containing EDTA, bile salts, and reducing thiols. Solvents containing EDTA, bile salts,
Scand $\mathcal{F}$ Gastroenterol 1989; 24: 373-80.

6 Thistle JL, May GR, Nelson PE, Peine CJ. Dissolution of cholesterol gallbladder stones using methyl tert-butyl ether. In: Paumgartner G, Stiehl A, Gerok W, eds. Bile acids and In: Paumgartner G, Stiehl A, Gerok W, eds. Bile acids and

7 the liver. Lancaster, England: MTP Press, 1987: 369-70. failure during dissolution of gallstones by methyl tert-butyl failure during dissolution of

8 Tazuma S, Nakai S, Mizuno S, Saraki H, Horiuchi I, 
Kajiyama G. A new approach for acute cholecystitis combined with rapid dissolution therapy of radiolucent gallstones using methyl tert-butyl ether (MTBE). Gastroenterology 1988; 84: A520.

9 Leuschner U, Wurbs D, Baugmärtel H, Helm EB, Classen M. Alternating treatment of common bile duct stones with a modified glyceril-1-monooctanoate preparation and a bile acid-EDTA solution by nasobiliary tube. Scand $\mathcal{F}$ Gastroenterol 1981; 16: 497-503.

10 Leuschner U, Wosiewitz U, Baugmärtel $\mathrm{H}$, et al. Dissolution of calcified cholesterol stones and of brown and black pigment stones of the gallbladder. Digestion 1988; 39: 100 10 .

11 Leuschner U, Baumgärtel H, Fischer H, David R, Leuschner $M$, Hübner $\mathrm{K}$. The dissolution of CBD cholesterol and pigment stones with methyl tert-butyl ether (MTBE) in vitro and in vivo. [Abstract]. Gastroenterology 1985; 88: 1674

12 Tritapepe R, DiPadova C, DiPadova F. Methyl tertiary-buty ether fails to dissolve cholesterol retained biliary tract stones. [Abstract]. Hepatology 1985; 5: 981 .

13 DiPadova C, DiPadova F, Montorsi W, et al. Methyl tertbutyl ether fails to dissolve retained radiolucent common bile duct stones. Gastroenterology 1986; 91: 1296-300.

14 Teplick StK, Haskin PH, Goldstein RC, et al. Common bile duct stone dissolution with methyl tert-butyl ether: duct stone dissolution with methyl tert-butyl ethe

15 Thistle JL, May GR, Bender CE, et al. Dissolution of cholesterol gallbladder stones by methyl tert-butyl ether cholesterol gallbladder stones by methyl tert-butyl ether administered by percutan 1989 ; 320: 633-9. 